\title{
Study on Clinching of Magnesium Alloy Sheets with Different Lower Die Parameters Based on DEFORM 2D
}

\author{
Shanling $\mathrm{Han}^{1, \mathrm{a}}$, Yiwei $\mathrm{Wu}^{1, \mathrm{~b}}$, Yuan $\mathrm{Gao}^{1}$, Qingliang Zeng ${ }^{1}$ \\ ${ }^{1}$ College of Mechanical and Electronic Engineering, Shandong University of Science and \\ Technology, Qingdao 266510, P.R.China \\ a'S.L.HAN@163.com, 'rlangjy1986@163.com
}

Keywords: magnesium alloy sheets, clinching, DEFORM 2D, lower die parameters, joint strength

\begin{abstract}
Clinching is a high-speed mechanical fastening technique which is suitable for joining lightweight sheet materials. In order to study the influence of lower die parameters on strength of joint, this paper presents the analysis of the clinching based on DEFORM 2D software. The lightweight, strong and durable, magnesium alloy sheets were carried out to be the joint materials, and the variation of changed process for die depth, groove fillet radius, groove depth, groove width and draft angle were analyzed. By studying the main geometrical parameters of clinched joint, the influence trend in the strength of joint were obtained by the single assessment process. The result indicated that the strength of joint can be effectively improved by suitably controlling the die parameters.
\end{abstract}

\section{Introduction}

The automotive industry is facing challenges on many lightweight materials that can significantly contribute to greater fuel economy and environmental protection. A variety of new materials also has been introduced as alternatives to the older ones, such as magnesium alloy, nonmetallic composite materials and engineering plastics[1]. Unfortunately, traditional joining methods like spot welding can only be used to a very limited extent to make connection between the parts mentioned above. However, the clinching technology has turned into a revolutionary influence on sheet metal connection in modern manufacturing industry[2].The clinching method has been shown to be a feasible alternative to spot welding for joining assemblies which involves coated, lightweight, and nonmetal materials. Moreover, the joint also exhibits excellent dynamic fatigue performance between the sheets to a greater degree than that of the prior process.

Israel. Markus [3] characterized that clinching can bring great benefits in terms of high efficiency, lower processing costs, reliable quality assurance and wide range of applications, and it is conceivable and desirable for automotive sector form thin sheet to thickness sheet. Coppieters. S [4] pointed out three failure mechanisms in clinched joints under pull-out loading, the paper also carried out an analytical approach to estimate the pull-out strength and a correction curve was derived which enables to adapt the analytical solution accounting. Neugebaue. $\mathrm{R}$ [5] presented that the formability of the magnesium alloy parts can be significantly improved when the temperature is in excess of 220 ${ }^{\mathrm{O}} \mathrm{C}$ than that at room temperature. Although the dynamic strength of clinched joint is superior to spot welding notably, the static strength only achieves up to $70 \%$ of a spot weld. Meanwhile, the behavior of static strength depends strongly on the lower die. Thus, to further enhance the joint strength, a basic model of clinching with magnesium alloy is established in this paper, and the results offer a better insight into the practical application of clinching.

\section{Principle of Clinching}

Clinching is a mechanical joining technique by which sheet metal parts can be locked together. A series cycle of tools is used in clinching process, as shown in Fig. 1. At the beginning of the joining process, which is shown in Fig. 1 (a), the blank holder is moved towards to compress the upper sheet. Then, the punch moves downward with a speed above a certain desired value into the sheets. The 
material of the sheets is pierced partially and the flow of the materials is in the opposite direction to the movement of the punch. When the sheet metal is completely filled in the ring groove of the die, the connection forms and an interlock is set up between the two metal sheets [6], as shown in Fig. 1 (b).

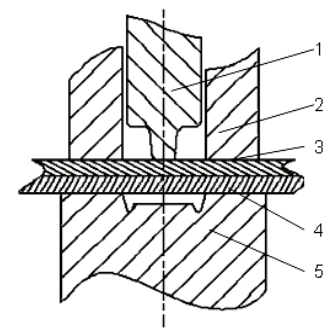

(a)

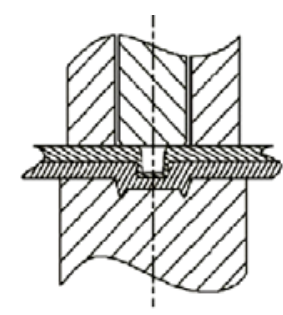

(b)

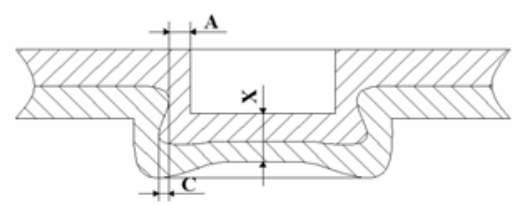

(a)

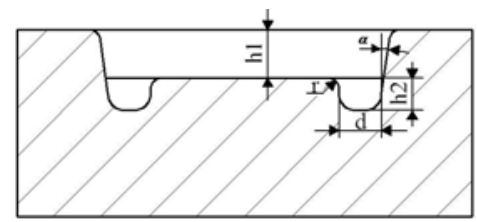

(b)
Fig. 1 The principle of clinching: 1-punch, 2-blank holder, 3-upper part, 4-bottom part, 5- lower die
Fig. 2 Main Geometrical parameters on the (a) joint: $C$-interlock, $A$-neck thickness, $X$-bottom thickness; (b) bottom Die: $h 1$-die depth, $h 2$-groove depth, $r$-groove fillet radius $d$-groove width, $\alpha$-draft angle

In general, the joint strength can be related to its cross-tension strength. For simplify, the quality of a clinched joint can be directly measured by the main geometrical parameters which involves in interlock, neck thickness and bottom thickness. Fig. 2 (a) shows the deformed structure of a clinched joint. The interlock $C$ determines the tensile strength, the neck thickness $A$ determines the shear strength, and the bottom thickness $X$ denotes the reduction of the sheets. Fig. 2 (b) shows the main parameters of lower die.

\section{Simulation Models and Conditions}

For purposes of decreasing the computation time during the clinching simulation, it has been decided to utilize a typical axial symmetry structure. The numerical computation have been performed in DEFORM 2D software, where a related grid window in procedure enable to adapt mesh refinement in the large deformation region. AZ31 magnesium alloy is defined for both of the upper sheet and the lower sheet in this paper and the properties of the material is shown in Table1. To further study the influence of different lower die parameters on the quality of clinched joint, it is important to establish a basic model and comparison ones, as listed in Table 2. The entire model is created by AUTOCAD software.

Table 1 Properties of the material

\begin{tabular}{cccccc} 
Material & Young's modulus/MPa & Poisson's ratio & Yield strength/MPa & Thickness $/ \mathrm{mm}$ & Temperature $/{ }^{\circ} \mathrm{C}$ \\
\hline AZ31 & 44800 & 0.35 & 220 & 0.8 & 220 \\
\hline
\end{tabular}

Table 2 Simulation models

\begin{tabular}{lll}
\hline Model & Basic model & Comparison model \\
\hline Die depth $/ h 1$ & 0.9 & $0.7,0.8,1.0,1.1$ \\
Groove depth $/ h 2$ & 0.2 & $0.1,0.3,0.4,0.5$ \\
Groove fillet radius $/ r$ & 0.6 & $0.5,0.7,0.8,0.9$ \\
Groove width $/ d$ & 0.8 & $0.7,0.9,1.0,1.1$ \\
Draft angle $/ \alpha$ & $0^{\circ}$ & $2^{\circ}, 5^{\circ}, 8^{\circ}, 10^{\circ}$ \\
\hline
\end{tabular}




\section{Results and Discussion}

Die Depth $h 1$. The paper uses the following die depth: $0.7 \mathrm{~mm}, 0.8 \mathrm{~mm}, 0.9 \mathrm{~mm}, 1.0 \mathrm{~mm}, 1.1 \mathrm{~mm}$, and maintains other parameters. The strength of the joint can be estimated by the geometrical parameters: interlock $C$, neck thickness $A$, bottom thickness $X$. The higher value the die depth $h 1$, the higher is the interlock $C$. But the neck thickness $A$ and bottom thickness $X$ is lower, and it is obvious for parameter $A$. It is shown in Fig. 3.

Groove Fillet Radius $r$. The following groove fillet radius: $0.1 \mathrm{~mm}, 0.2 \mathrm{~mm}, 0.3 \mathrm{~mm}, 0.4 \mathrm{~mm}$, $0.5 \mathrm{~mm}$ is used for simulation. The results, as shown in Fig. 4, reveals that the groove fillet radius $r$ has a little effect on the interlock $C$, neck thickness $A$ and bottom thickness $X$.
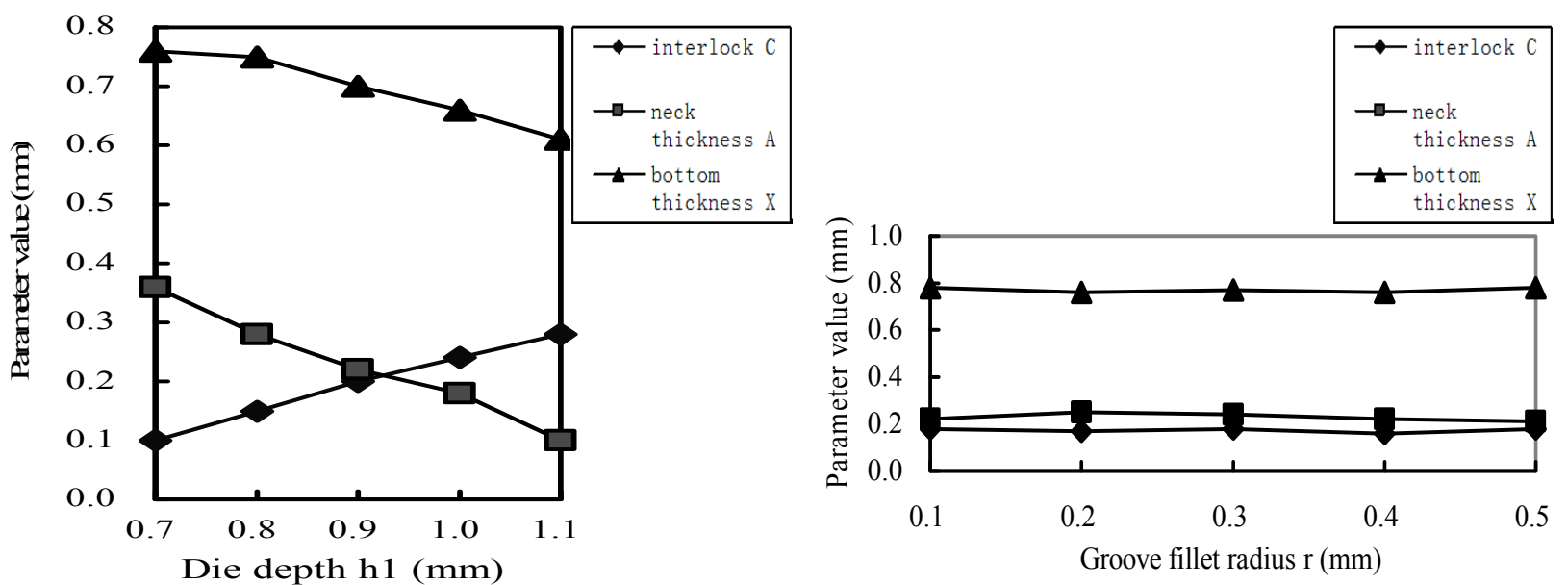

Fig. 3 Simulation results of the different die depth

Fig. 4 Simulation results of the different groove fillet radius

Groove Depth $h 2$. Groove depth $h 2$ has little effect on neck thickness $A$, as illustrated in Fig. 5(a). Owing to the small size of the groove depth, the lower sheet's insufficient flow into the groove can lead to a small interlock. An increase in groove depth $h 2$ leads to an increase in interlock $C$, Meanwhile, due to the upper sheet flows into the groove increased, bottom thickness $X$ decreased correspondingly. However, when groove depth $h 2$ is more than $0.8 \mathrm{~mm}$, the clinched joint can lead to an unexpected clearance, for a further depth of $0.9 \mathrm{~mm}$, the clearance is even larger, as shown in Fig. $5(\mathrm{~b})$ (c). The reason is mainly because the deformation for the upper sheet can not keep up with the lower sheet that flows into the groove.

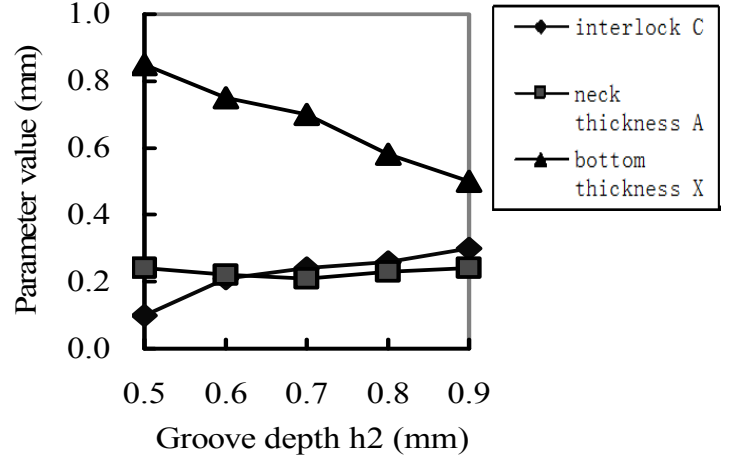

(a)

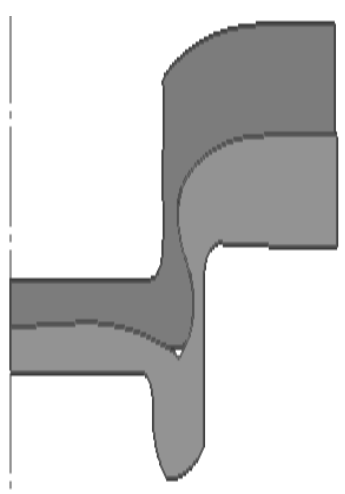

(b)

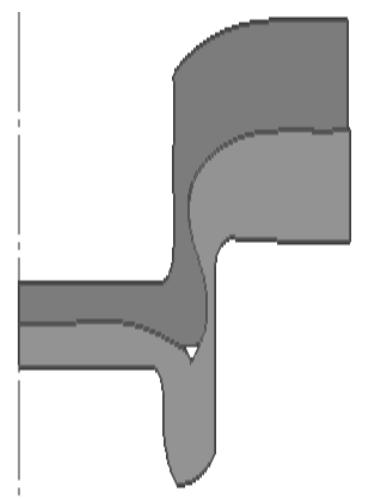

(c)

Fig. 5 Simulation results of the different groove depth

Groove Width $d$. When analyzing the joint strength vs. groove width $d$, As can be seen from Fig. 6 , it can be said that the groove width $d$ have important effect. The neck thickness and bottom thickness has been declining, while the interlock is fluctuated. Therefore, the lower die should be 
designed in accordance with the pressing process of clinched joint. Consequently, it is necessary to consider both interlock and neck thickness to design the groove width of lower die for the improvement of general joint performance.

Draft Angle $\alpha$. As shown in Fig. 7, the neck thickness increases along with the draft angle, and the interlock and bottom thickness generally decline with draft angle. However this decline is not apparent for interlock over small ranges. So in actual design, to facilitate taking out the clinched joint from the lower die, it is reasonable to make draft angle equal to $2^{\circ} \sim 5^{\circ}$ in general.

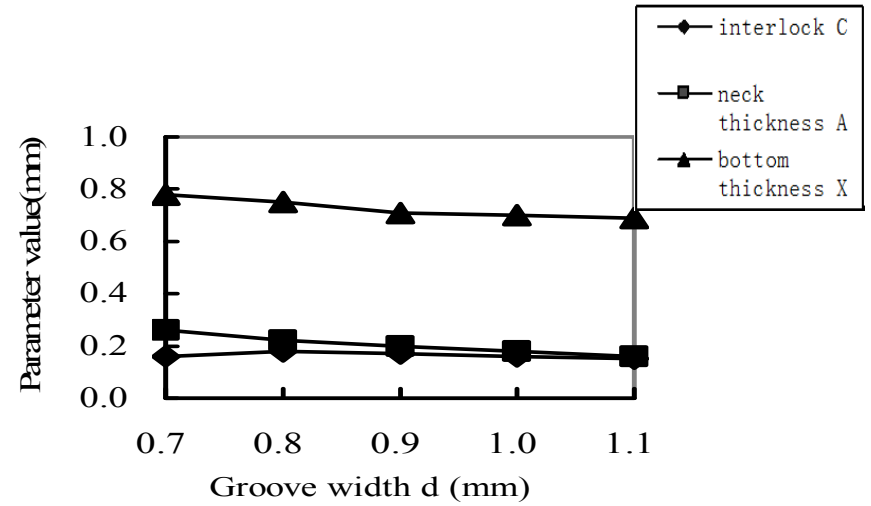

Fig. 6 Simulation results of the different groove width

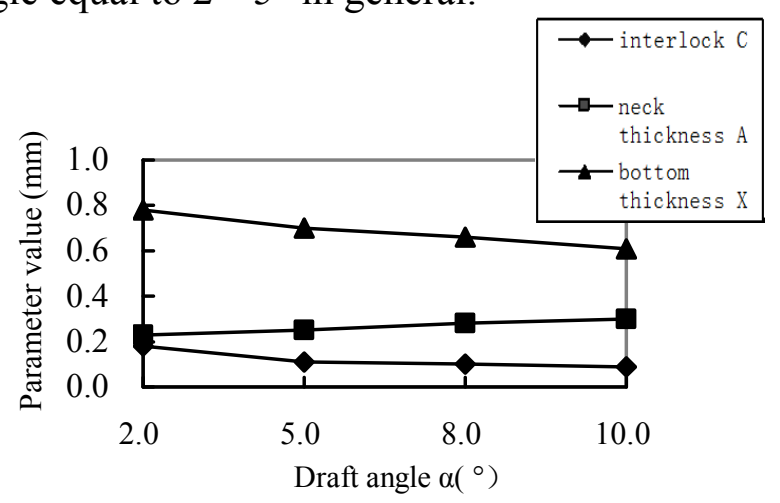

Fig. 7 Simulation results of the different draft angel

\section{Summary}

Due to the strength of clinched joint to a large extent depends on the geometrical parameters, which is influenced by the lower die parameters, the clinching process of magnesium alloy is simulated to study the influence of the die based on DEFORM 2D in this paper. The result shows that the die depth and groove depth have more critical effect on the strength of joint than the effect of groove fillet radius, groove width and draft angle. It is also indicates that the strength of the joint can be effectively improved by suitably controlling the die parameters. This can provide certain guidance to the practical application of clinching.

\section{Acknowledgement}

This work was financially supported by Project for Post Doctoral Innovation of Shandong Province (201003036), Open Fund of Shanghai Key Lab of Digital Auto body Engineering (2011003), and Project for postgraduate Innovation of Shandong University of Science and Technology (YCA120105).

\section{References}

[1] R. A. Witik, J. Payet, V. Michaud, C. Ludwig, J. A. E. Manson: Compos Part A Appl Sci and Manuf. Vol. 42 (2011), p. 1694-1709

[2] O. Hahn and U. Klemens, in: Fügen durch Umformen: Nieten und Durchsetzfügen-Innovative Verbindungsverfahren für die Praxis, Chemical Industry Publishers (2005).

[3] M. Israel, F. Jesche, R. Mauermann, A.Trojer: Stahlbau. Vol. 79 (2010), p. 510-514

[4] S. Coppieters, P.Lava, S. Baes, H. Sol, P. Van Houtte and D.Debruyne: Thin-Wall Struct. Vol. 52 (2012), P. 42-52

[5] R. Neugebauer, C. Kraus, S. Dietrich, Advances in mechanical joining of magnesium[J]. CIRP Annals - Manufacturing Technology, 2008, 57(1): 283-286

[6] S. L. Han, Y. W. Wu and Q. L. Zeng: Advanced Materials Research, Vol. 472 (2012), p. 1995-1999 